\title{
BLICKDIAGNOSE
}

Stellen Sie uns

Ihren Fall vor.

Bei Veröffentlichung erhalten Sie 100 Euro!

cornelius.heyer@ springer.com

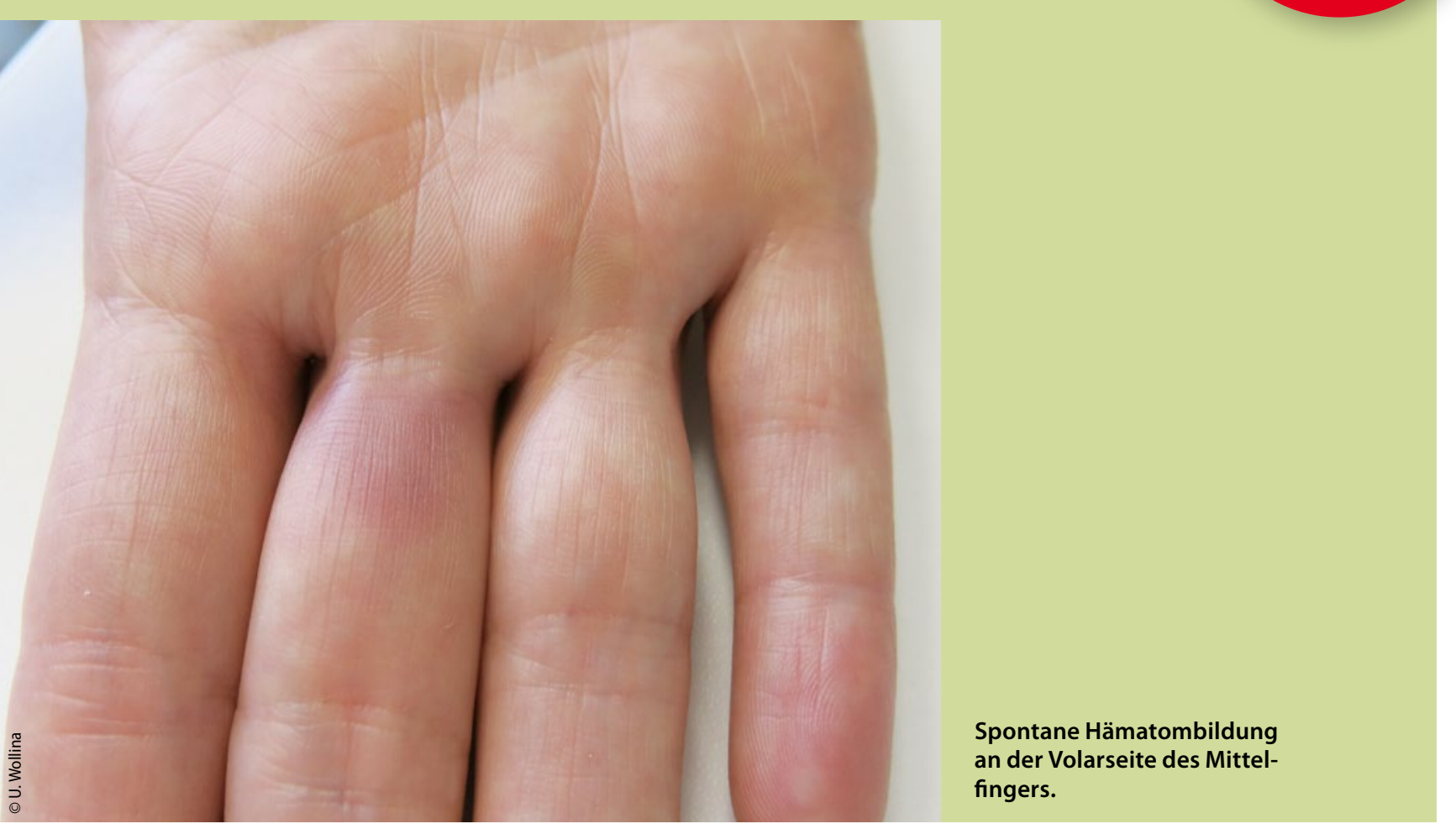

Unangenehme Missempfindungen

\section{Woher kommen die Schmerzen und Hämatome?}

- Bei einer 42-jährigen, ansonsten gesunden Patientin kam es seit etwa neun Monaten wiederholt zum Aufschießen schmerzhafter subkutaner Knoten an den Volarseiten einzelner Finger. Aus diesen entwickelte sich innerhalb weniger Stunden ein Hämatom, welches mit brennenden Missempfindungen einherging. Die Patientin war Nichtraucherin und nahm nur selten Kopfschmerztabletten ein.

Stets war nur ein einzelner Finger betroffen, am häufigsten die Mittel- und Zeigefinger. Die Symptome verschwanden innerhalb weniger Tage vollständig. Die Abstände zwischen den Episoden zeigten keinerlei Regelhaftigkeit.

Die Diagnose lautete Achenbach-Syndrom. Die Erkrankung ist durch spontane paroxysmale Schwellungen, Schmerzen, Parästhesien und Hämatome meist an den Fingern, seltener an den Zehen gekennzeichnet. Frauen im mittleren Lebensalter sind häufiger betroffen. Minortraumen und die Einnahme ergotaminhaltiger Medikamente werden als Auslöser diskutiert. Die Ruptur kleinster Venen stellt eine weitere Hypothese dar. Blutgerinnung und Doppler-Sonografie sind unauffällig.
Kleinste Blutungen sind in der Kapillarmikroskopie sichtbar. In Einzelfällen wurde ein reduzierter digitaler Blutfluss im Angiogramm beobachtet.

Differenzialdiagnostisch sind das Raynaud-Phänomen (zweiphasige Reaktion auf Kältereiz), das erythrozytäre Sensibilisierungssyndrom (Painful-Bruising-Syndrome; eher an den Beinen und am Rumpf), eine Spontanruptur der Vincula tendinum, Purpura senilis, die seltene Thrombophlebitis einer Fingervene, eine Dermatitis artefacta oder auch Traumata zu bedenken.

Die benigne und selbstlimitierte Erkrankung kann durch sorgfältige klinische Untersuchung und Anamneseerhebung diagnostiziert werden. So können unnötige Untersuchungen des Labors und der Bildgebung vermieden werden. Der Patient sollte dahingehend beruhigt werden, dass eine ernsthafte Erkrankung auszuschließen ist. Die Akutbehandlung besteht im Kühlen.

\footnotetext{
$\rightarrow$ Prof. Dr. med. Uwe Wollina
}

Klinik für Dermatologie und Allergologie, Krankenhaus DresdenFriedrichstadt, Städtisches Klinikum, Friedrichstr. 41, D-01067 Dresden 